\title{
Comparison of injury incidences between football teams playing in different climatic regions
}

This article was published in the following Dove Press journal:

Open Access Journal of Sports Medicine

4 December 2013

Number of times this article has been viewed

\section{John W Orchard' \\ Markus Waldén ${ }^{2}$ \\ Martin Hägglund ${ }^{3}$ \\ Jessica J Orchard' \\ Ian Chivers ${ }^{4}$ \\ Hugh Seward ${ }^{5}$ \\ Jan Ekstrand ${ }^{2}$}

'School of Public Health, University of Sydney, Sydney, NSW, Australia; ${ }^{2}$ Department of Medical and Health Sciences, Division of Community Medicine, Linköping University, Linköping, Sweden; ${ }^{3}$ Department of Medical and Health Sciences, Division of Physiotherapy, Linköping University, Linköping, Sweden; ${ }^{4}$ Native Seeds, Cheltenham, VIC, Australia; ${ }^{5}$ Australian Football League Medical Officers

Association, Melbourne, VIC, Australia

Video abstract

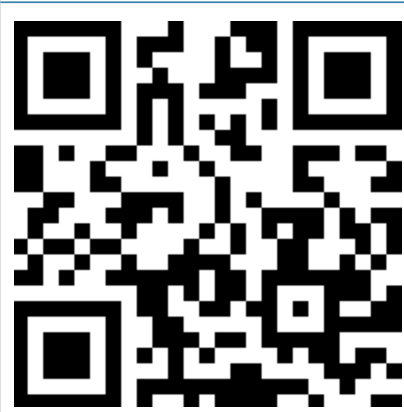

Point your SmartPhone at the code above. If you have a QR code reader the video abstract will appear. Or use: http://dvpr.es/168B4Ni

Correspondence: John W Orchard Sports Medicine, University of Sydney, Corner Western Ave \& Physics Rd, Sydney, NSW 2006, Australia Email johnworchard@gmail.com
Abstract: Australian Football League (AFL) teams in northern (warmer) areas generally have higher rates of injury than those in southern (cooler) areas. Conversely, in soccer (football) in Europe, teams in northern (cooler) areas have higher rates of injury than those in southern (warmer) areas, with an exception being knee anterior cruciate ligament (ACL) injuries, which are more common in the southern (warmer) parts of Europe. This study examined relative injury incidence in the AFL comparing 9,477 injuries over 229,827 player-weeks from 1999-2012. There was a slightly higher injury incidence for teams from warmer parts of Australia (relative risk [RR] 1.05, 95\% confidence interval [CI] 1.01-1.10) with quadriceps strains (RR 1.32, 95\% CI 1.10-1.58), knee cartilage injuries (RR 1.42, 95\% CI 1.16-1.74), and ankle sprains (RR 1.17, 95\% CI 1.00-1.37) all being more likely in warmer region teams. Achilles injuries followed a reverse pattern, tending to be more common in cooler region teams (RR 0.70, 95\% CI 0.47-1.03). In conclusion, common findings from the AFL and European soccer are that ankle sprains and ACL injuries are generally more likely in teams playing in warmer climate zones, whereas Achilles tendinopathy may be more likely in teams playing in cooler zones. These injuries may have climate or surface risk factors (possibly related to types and structure of grass and shoe-surface traction) that are universal across different football codes.

Keywords: climate, grass, shoe-surface traction, Australian football, soccer

\section{Introduction}

Matches in the different football codes (including soccer and Australian football) traditionally take place on natural grass, although artificial turf is a common substitute in American football, ${ }^{1}$ and is increasingly popular in soccer. ${ }^{2}$ Most comparison studies between different surface types have compared natural grass to artificial turf, with pooled results often inconclusive. ${ }^{2-5} \mathrm{~A}$ problem with comparisons is that natural grass surface conditions (Figures 1-11) are so variable (depending on type of grass, weather conditions, stage of season, and whether turf is mature or recently relaid). The few previous studies involving different conditions of natural grass surfaces have suggested some potential external risk factors for knee anterior cruciate ligament (ACL) injuries: ryegrass surfaces ${ }^{6}$ and recent rainfall ${ }^{7}$ may be protective; whereas recent warm weather ${ }^{7}$ or the recent laying of portable grass (Figures 12-14) ${ }^{8}$ may increase the risk of ACL injuries.

A starting point for comparison of different natural grass surface types is to examine injury rates in different climate zones, where different turfgrasses predominate. A turfgrass is a variety of grass used for areas of high traffic (such as playing fields or lawns) with good ability to regrow after wear through usage. Turfgrasses can be 


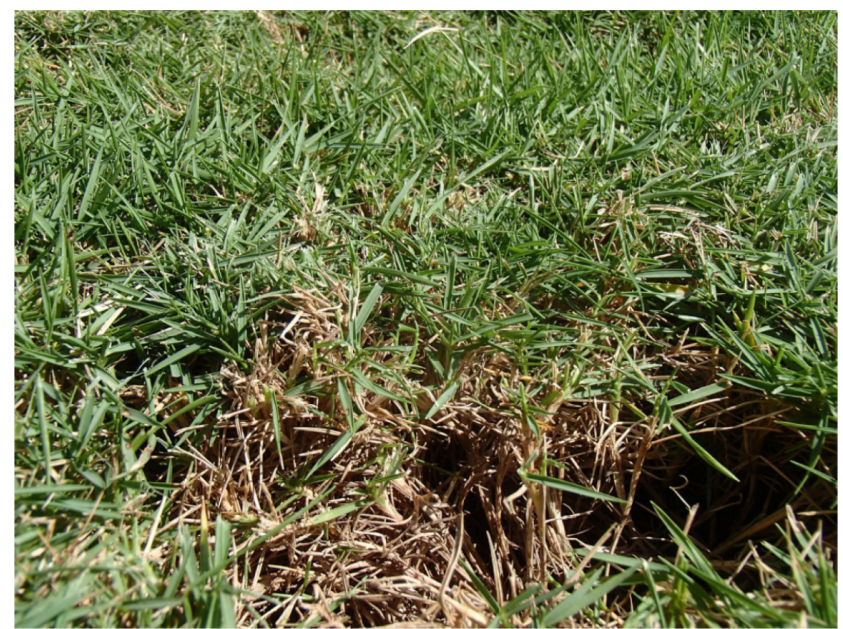

Figure I A warm-season grass showing a very thick thatch layer between the leaves and the soil.

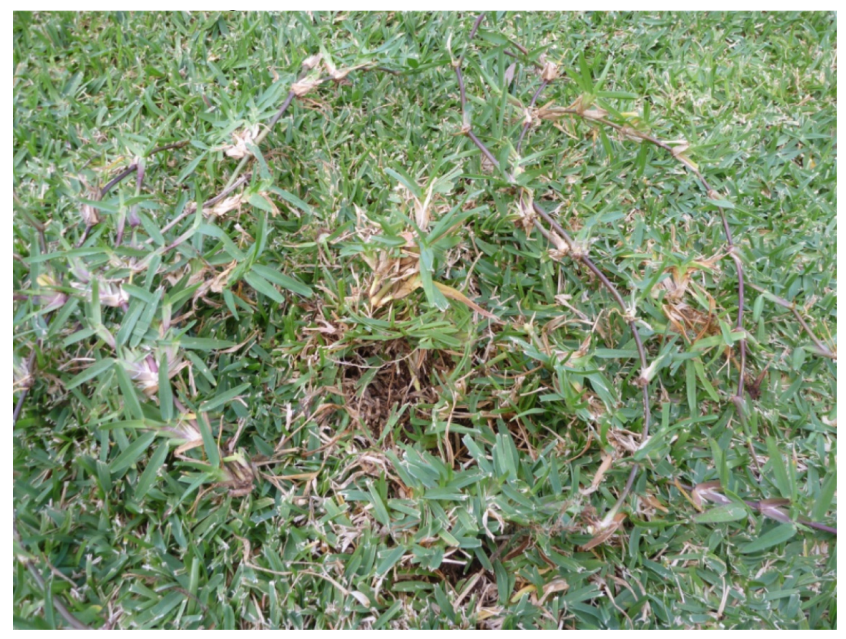

Figure 2 Stolons (above ground lateral growth) removed and displayed above the leaves of a warm-season grass.

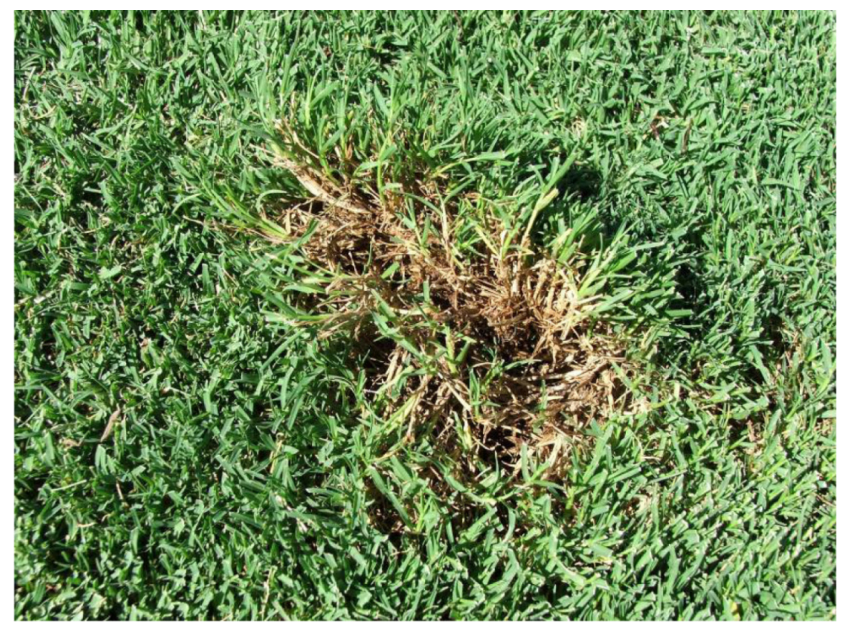

Figure 3 Hybrid Bermuda grass (Cynodon dactylon $\times$ Cynodon transvaalensis).

Notes: Warm-season turfgrass. Generally high thatch levels in this grass profile.

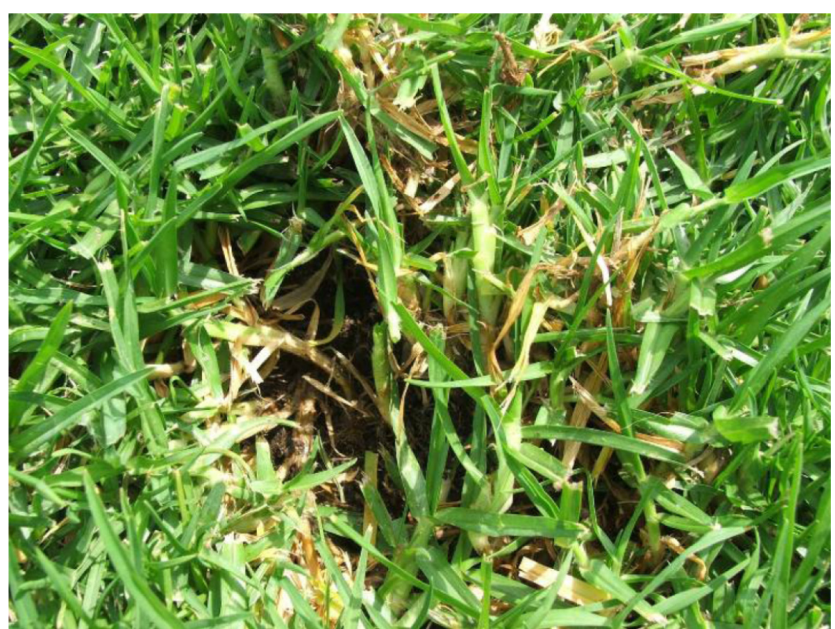

Figure 4 Kikuyu grass (Pennisetum clandestinum)

Notes: Warm-season turfgrass. Generally high thatch levels in this grass profile.

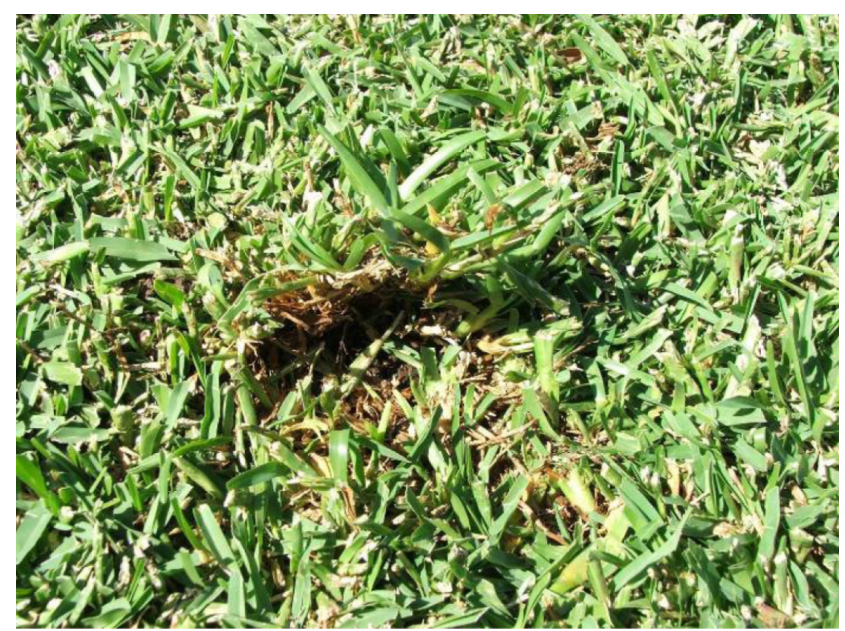

Figure 5 Buffalo grass (Stenotaphrum secundatum).

Notes: Warm-season turfgrass. Generally high thatch levels in this grass profile.

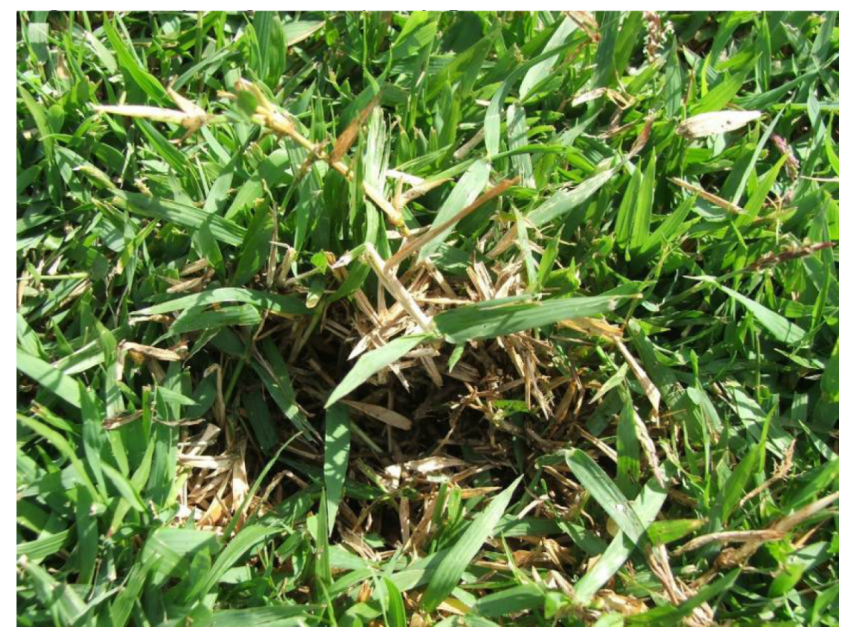

Figure 6 Zoysia grass (Zoysia japonica).

Notes: Warm-season turfgrass. Generally high thatch levels in this grass profile. 


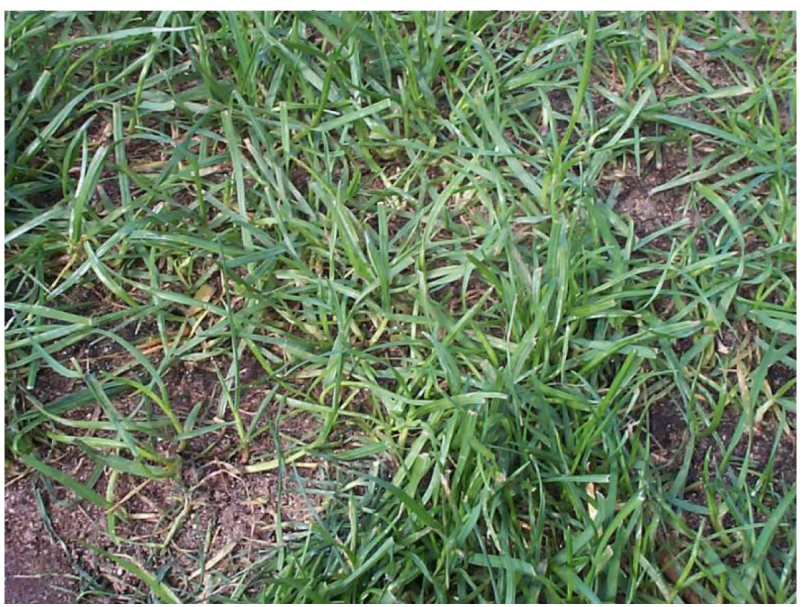

Figure 7 Perennial ryegrass (Lolium perenne).

Notes: Cool-season grass species. Relative lack of thatch in this figure compared to those in Figures 3-6.

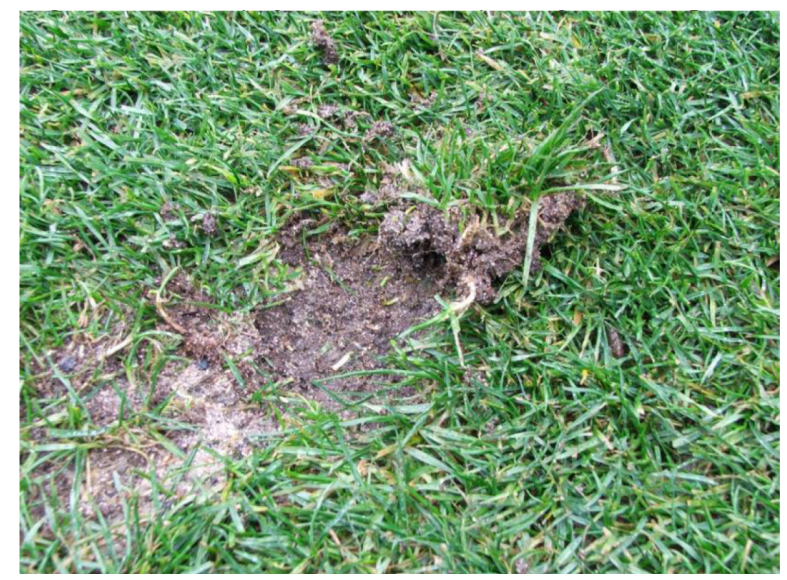

Figure 8 Mix of ryegrass and Kentucky bluegrass (Poa pratensis).

Notes: Cool-season grass species. Relative lack of thatch in this figure compared to those in Figures 3-6.

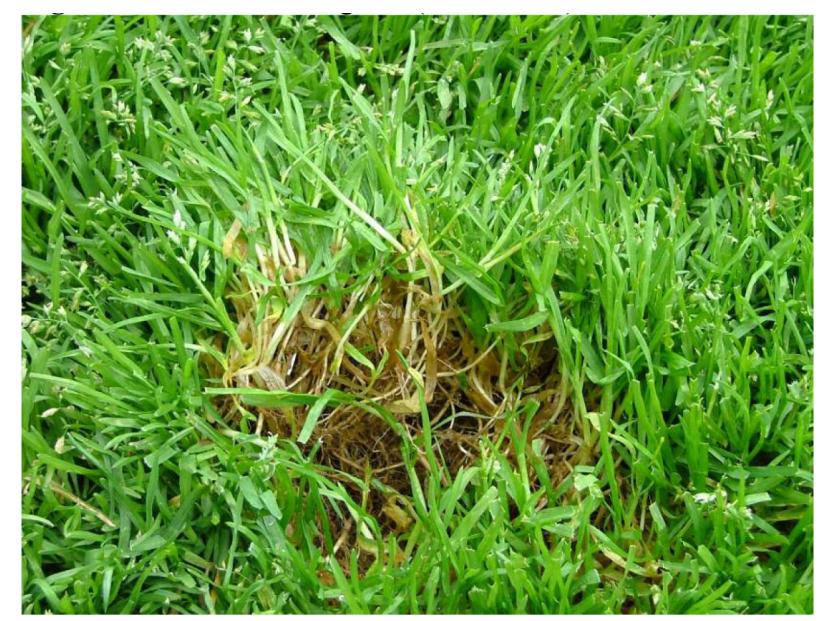

Figure 9 Annual winter grass (Poa annua).

Notes: Cool-season grass species. Relative lack of thatch in this figure compared to those in Figures 3-6.

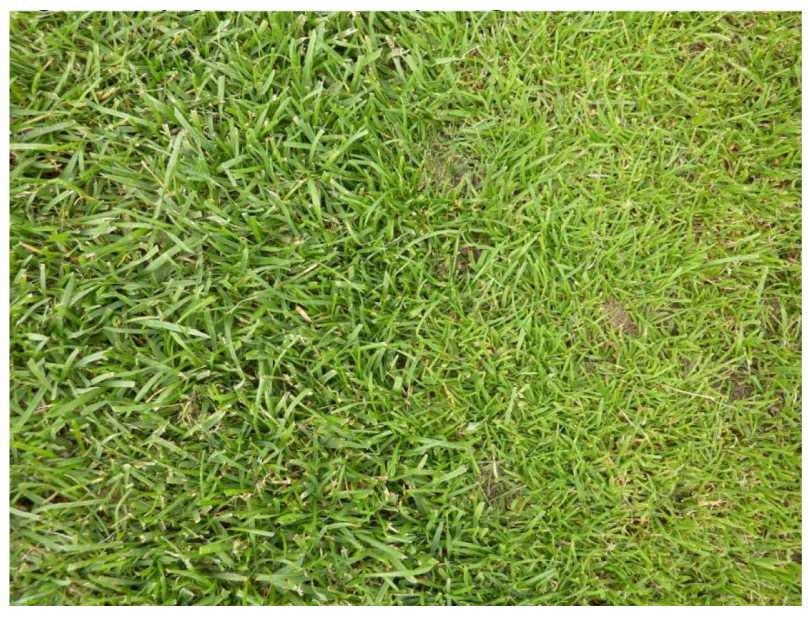

Figure I 0 Ryegrass and Kentucky bluegrass.

Notes: Cool-season grass species. Relative lack of thatch in this figure compared to those in Figures 3-6.

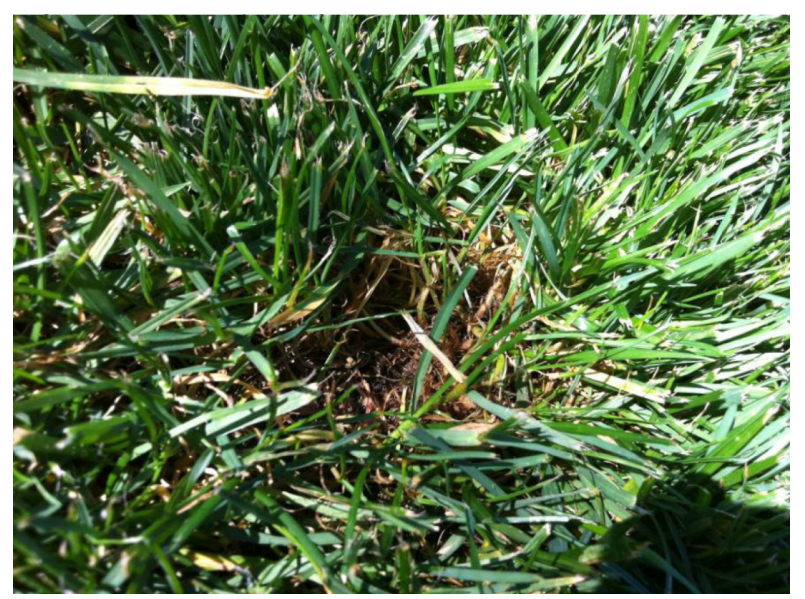

Figure I I Kentucky bluegrass and tall fescue (Festuca arundinacea) mix.

Notes: Cool-season grass species. Relative lack of thatch in this figure compared to those in Figures 3-6.

grouped into warm-season (Figures 1-6) and cool-season (Figures 7-11) varieties, with the warm-season grasses thriving in warmer climates and the summer months. In temperate zones, warm-season grasses are often used in summer and oversown with cool-season grasses in autumn, the timing of which depends on the point of the season at which average temperatures transfer to a level that better promotes the cool-season grasses. Warm-season grasses are generally more vigorous in their growth and generally lead to higher amounts of thatch (Figure 1) because of greater horizontal growth (Figure 2) than the cool-season turfgrasses. The nature of the playing surface provided by warm-season and cool-season grasses does vary in general terms and could theoretically form the basis for differences in injury rates in different climate zones. 


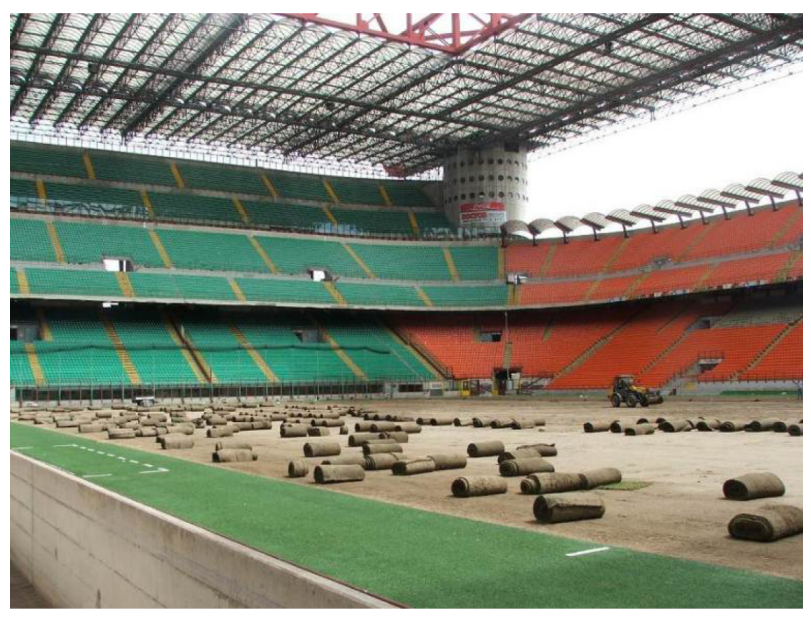

Figure 12 Portable natural grass being laid in rolls at the San Siro, Milan.

The difficulty in using epidemiology to compare injury rates in different climate zones is the large possible number of confounders. In different countries, football codes are played to varying degrees, with varying lengths of playing season and levels of play. In national population studies, ${ }^{9}$ for example, Australia ${ }^{10}$ has been found to have a higher rate of ACL injuries than New Zealand (with a cooler climate than Australia), ${ }^{11}$ which itself has a higher rate than the UK (with a cooler climate still). ${ }^{12}$ This suggests that warmer climates lead to higher ACL injury rates, but there are major confounders in terms of the amounts and types of sport played in these countries, which could also be responsible for the different rates.

The best studies to eliminate as many confounders as possible are those in which a single competition involves teams from different climate zones, as this limits the variation in exposure. In the Australian Football League (AFL), an increased risk of ACL injuries has been found on grounds

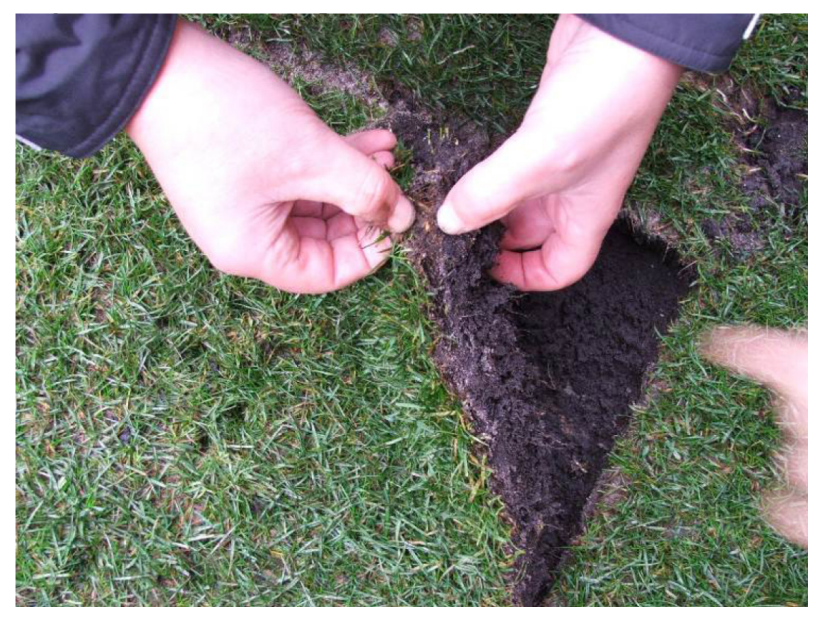

Figure I 3 Portable squares being laid at the Nou Camp, Barcelona.

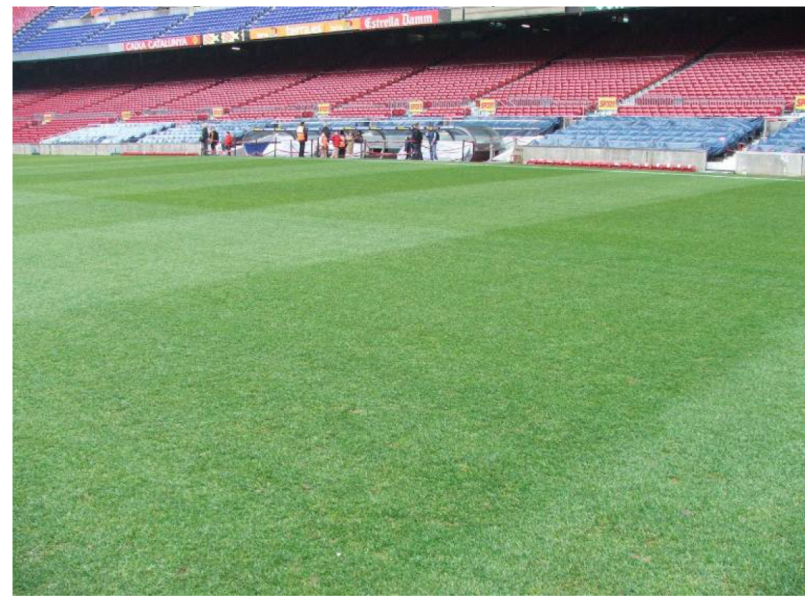

Figure 14 Squares in situ with no joins visible surface.

that are further to the north of Australia, ie, in a warmer climate (Figure 15), ${ }^{67,13}$ with higher injury rates overall in the warmer-climate teams. ${ }^{13}$ Further analysis of AFL injuries reveals that the rate of ACL injury is significantly lower on grounds that have perennial ryegrass (Figure 7) as the major species, compared to Bermuda grass (Figure 3). ${ }^{6,14}$

In European soccer (football), ACL injuries follow a similar trend and are significantly more common in the southern (warmer) teams (Figure 16). ${ }^{15}$ However, the teams whose home games are in cooler climates generally have a higher overall injury rate than those from warmer climates, ${ }^{15,16}$ which is in contrast to the trend found in the AFL. The inconsistency of the findings between the AFL and the Union of European Football Associations (UEFA) football competitions for injuries in general suggests that competing factors - climatic and perhaps cultural - are interacting. Further research is therefore required to ascertain the trends and the underlying reasons for the observations.

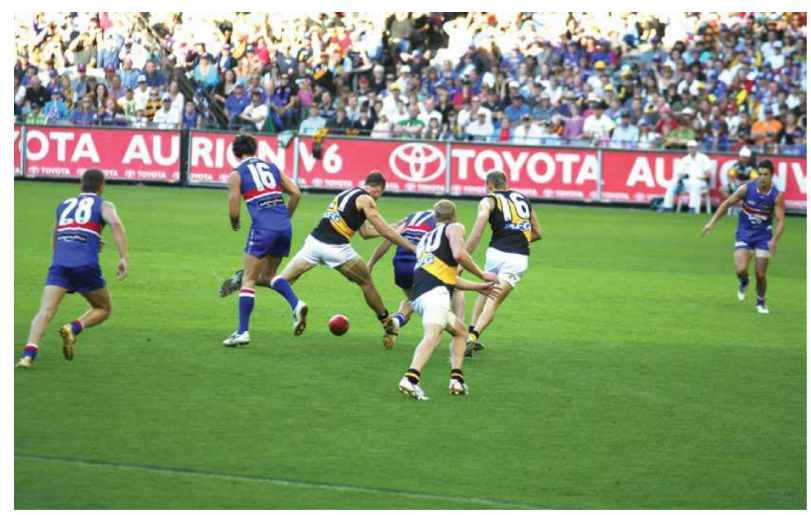

Figure I5 An Australian Football League match being played outdoors on natural grass. 


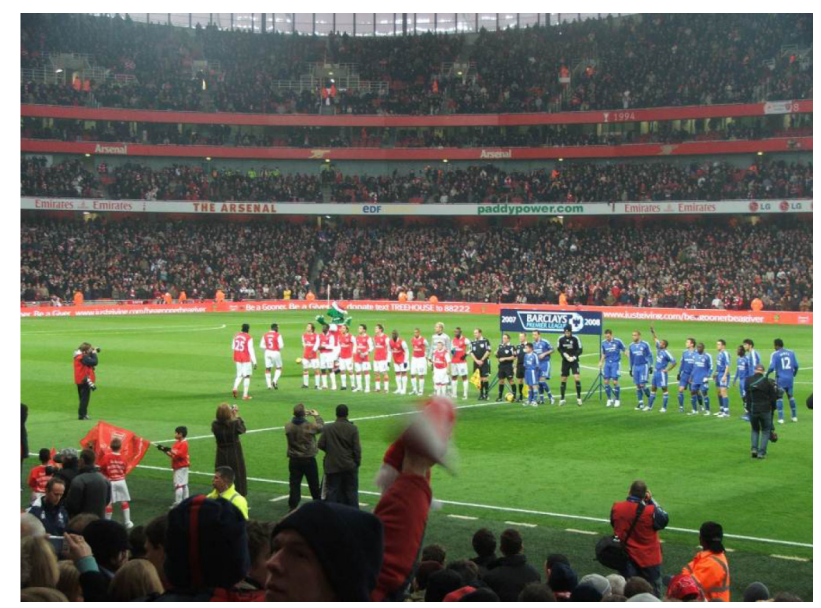

Figure 16 European football (soccer) played at the Emirates Stadium in London.

The purpose of the present study was to examine AFL injury rates in the northern (warmer) and southern (cooler) parts of Australia using updated surveillance data and to compare this with recently published data from European soccer studies.

\section{Materials and methods}

The new data provided for this study were extracted from the AFL injury database according to methods that have been previously described. ${ }^{17,18}$ Players were de-identified, with the injury diagnosis and team played for as the primary risk factors that were analyzed. The methods used for this study were noninterventional and conform to the Code of Ethics of the World Medical Association (Declaration of Helsinki) and Australia's National Health and Medical Research Council (NHMRC) guidelines. The methods for data collection were very similar to a previous study from the AFL, covering seasons $1992-1998$, inclusive..$^{13}$ The definition for an injury had been chosen as any condition that causes a player to miss a regular season or finals match. The start date for this current study was chosen as season 1999, so as to not overlap with data from the previous study. ${ }^{13}$

The teams for this study were grouped into two climate zones according to the Köppen-Geiger classification (Table 1). ${ }^{19}$ The Köppen-Geiger system is divided into five different climate types (A-E) based on the average monthly temperature and precipitation. Each main category is further divided into several subtypes by adding two lower case letters; the first letter refers to the precipitation and the second letter refers to the air temperature. In Australia, the dominating climate types are: Mediterranean, with warm/ hot and dry summer together with wet winter; Humid Subtropical (Cfa), with hot humid summer and cool winter; and
Table I Categorization of teams into climate zones

\begin{tabular}{|c|c|c|}
\hline & Northern (warmer) & Southern (cooler) \\
\hline Teams & $\begin{array}{l}\text { Adelaide, Brisbane, } \\
\text { Fremantle, Gold } \\
\text { Coast, Port Adelaide, } \\
\text { Sydney, West Coast }\end{array}$ & $\begin{array}{l}\text { Carlton, Collingwood, } \\
\text { Essendon, Geelong, } \\
\text { Hawthorn, Melbourne, } \\
\text { North Melbourne, } \\
\text { Richmond, St Kilda, } \\
\text { Western Bulldogs }\end{array}$ \\
\hline $\begin{array}{l}\text { Cities/towns where } \\
\text { home games are } \\
\text { typically played }\end{array}$ & $\begin{array}{l}\text { Brisbane, Gold } \\
\text { Coast, Sydney, } \\
\text { Adelaide, Perth }\end{array}$ & $\begin{array}{l}\text { Melbourne, Geelong, } \\
\text { Launceston }\end{array}$ \\
\hline Climate zones & $\begin{array}{l}\text { Csa - Adelaide, Perth; } \\
\text { Cfa - Brisbane, Gold } \\
\text { Coast, Sydney }\end{array}$ & $\mathrm{Cfb}$ \\
\hline $\begin{array}{l}\text { Predominant grass } \\
\text { surface }\end{array}$ & $\begin{array}{l}\text { Bermuda grass } \pm \\
\text { early-mid season } \\
\text { ryegrass oversow } \\
\text { (warm-season } \\
\text { dominant) }\end{array}$ & $\begin{array}{l}\text { Ryegrass or Bermuda } \\
\text { grass base with } \\
\text { preseason ryegrass } \\
\text { oversow (cool-season } \\
\text { dominant) }\end{array}$ \\
\hline Traction levels & Medium-high & Low-medium \\
\hline
\end{tabular}

Abbreviations: Cfa, Humid Subtropical; Cfb, Maritime Temperate; Csa, Mediterranean.

Maritime Temperate (Cfb), with warm summer but no dry season. Perth and Adelaide are classified as Mediterranean climate type, which in Europe is found in Portugal, Spain, most of Italy, and the southern parts of France. Sydney, Brisbane, and the Gold Coast are classified as Cfa climate type, which in Europe is found in northern Italy. Melbourne and Geelong are classified as $\mathrm{Cfb}$ climate type, which in Europe corresponds to most of Great Britain, Belgium, The Netherlands, and Germany.

The primary unit of comparison was injury incidence in a unit of injuries per team per season. ${ }^{17}$ These units include adjustments for different player roster sizes and match schedules, so that the unit is based on a 40-player roster competing in 22 matches per season. The relative risk between the two zones was calculated with $95 \%$ CIs to determine statistical significance at the $P<0.05$ level.

A match consists of 80 minutes of playing time plus a lengthy amount of time added for stoppages (up to a further 40 minutes). In addition to match exposure, an average player would physically train for 6-10 hours per week, depending on the definition of training (ie, whether gym training and technique training was added to aerobic-type training).

For comparison with the AFL data, further data were extracted from a recently published study involving European soccer teams. ${ }^{15}$ The data presented in this study are from the exact same dataset from this previous study; however, for the most valid comparison, the data were filtered to only include injuries that caused a match to be missed (which was the definition used for the AFL data). In a similar fashion to 
the AFL, these data are presented as relative risk comparisons of injury incidence for the warmer-climate-based teams compared to the cooler-climate-based teams.

\section{Results}

Table 2 shows the differences in injury incidence between the zones for the major injury categories. There was a very slight but significant increase in injury incidence in the warmer region teams, which suffered 5\% more injuries than the cooler region teams over the 14 seasons.

The injury categories where the northern teams were significantly more likely to suffer injuries were quadriceps strains, knee cartilage injuries, and ankle sprains or joint injuries. Achilles tendon injuries followed a reverse trend and

Table 2 Injury incidence comparison of northern AFL teams to southern AFL teams from 1999-20I2, inclusive

\begin{tabular}{|c|c|c|c|c|c|c|}
\hline \multirow[t]{3}{*}{ Body area } & \multirow[t]{3}{*}{ Injury category } & \multicolumn{2}{|c|}{ Injury incidence } & \multirow{3}{*}{$\begin{array}{l}\text { RR } \\
\text { N:S } \\
\text { (warm:cool) }\end{array}$} & \multicolumn{2}{|c|}{$95 \% \mathrm{Cl}$} \\
\hline & & \multirow{2}{*}{$\begin{array}{l}\text { Northern } \\
\text { warmer } \\
\text { Csa, Cfa } \\
\end{array}$} & \multirow{2}{*}{$\begin{array}{l}\text { Southern } \\
\text { cooler } \\
\text { Cfb }\end{array}$} & & \multirow[t]{2}{*}{ Low } & \multirow[t]{2}{*}{ High } \\
\hline & & & & & & \\
\hline \multirow[t]{5}{*}{ Head/neck } & Concussion & 0.6 & 0.5 & 1.24 & 0.89 & I.71 \\
\hline & Facial fractures & 0.6 & 0.5 & 1.16 & 0.82 & 1.65 \\
\hline & Neck sprains & 0.1 & 0.1 & 1.03 & 0.51 & 2.07 \\
\hline & Other head and neck injuries & 0.2 & 0.2 & 1.09 & 0.60 & 2.00 \\
\hline & All head/neck & 1.5 & 1.3 & 1.17 & 0.95 & 1.45 \\
\hline \multirow[t]{6}{*}{ Shoulder/arm/elbow } & Shoulder sprains and dislocations & 1.2 & 1.3 & 0.96 & 0.77 & 1.20 \\
\hline & $A C$ joint injuries & 0.8 & 0.8 & 0.93 & 0.71 & 1.24 \\
\hline & Fractured clavicles & 0.3 & 0.3 & 1.20 & 0.75 & 1.91 \\
\hline & Elbow sprains or joint injuries & 0.2 & 0.2 & 1.01 & 0.54 & 1.90 \\
\hline & Other shoulder/arm/elbow injuries & 0.4 & 0.4 & 0.93 & 0.63 & 1.39 \\
\hline & All shoulder/arm/elbow & 2.9 & 2.9 & 0.97 & 0.84 & 1.13 \\
\hline \multirow[t]{3}{*}{ Forearm/wrist/hand } & Forearm/wrist/hand fractures & 1.0 & 1.2 & 0.86 & 0.68 & 1.10 \\
\hline & Other hand/forearm/wrist injuries & 0.4 & 0.4 & 0.95 & 0.65 & 1.40 \\
\hline & All forearm/wrist hand & 1.4 & 1.6 & 0.89 & 0.72 & 1.09 \\
\hline \multirow[t]{4}{*}{ Trunk/back } & Rib and chest wall injuries & 0.6 & 0.6 & 0.91 & 0.66 & 1.25 \\
\hline & Lumbar and thoracic spine injuries & 1.6 & 1.4 & 1.19 & 0.98 & 1.46 \\
\hline & Other buttock/back/trunk injuries & 0.7 & 0.6 & 1.15 & 0.84 & 1.58 \\
\hline & All trunk/back & 2.9 & 2.6 & I.II & 0.96 & 1.29 \\
\hline \multirow[t]{6}{*}{ Hip/groin/thigh } & Groin strains and osteitis pubis & 3.4 & 3.2 & 1.09 & 0.95 & 1.24 \\
\hline & Hamstring strains & 6.0 & 5.9 & 1.02 & 0.92 & 1.13 \\
\hline & Quadriceps strains & 2.1 & 1.6 & 1.32 & 1.10 & $1.58 *$ \\
\hline & Thigh and hip hematomas & 0.8 & 0.9 & 0.91 & 0.69 & 1.20 \\
\hline & Other hip/groin/thigh injuries & 0.5 & 0.6 & 0.88 & 0.63 & 1.23 \\
\hline & All hip/groin/thigh & 12.9 & 12.1 & 1.06 & 0.99 & 1.14 \\
\hline \multirow[t]{8}{*}{ Knee } & $\mathrm{ACL}$ & 0.8 & 0.7 & 1.09 & 0.82 & 1.46 \\
\hline & $\mathrm{MCL}$ & I.I & 0.9 & 1.20 & 0.94 & 1.54 \\
\hline & $\mathrm{PCL}$ & 0.4 & 0.5 & 0.70 & 0.48 & 1.04 \\
\hline & Knee cartilage & 1.7 & 1.2 & 1.42 & 1.16 & $1.74 *$ \\
\hline & Patella injuries & 0.2 & 0.3 & 0.77 & 0.46 & 1.30 \\
\hline & Knee and patella tendon injuries & 0.6 & 0.5 & 1.17 & 0.85 & 1.62 \\
\hline & Other knee injuries & 0.9 & 0.7 & 1.33 & 1.01 & $1.76 *$ \\
\hline & All knee & 5.7 & 4.8 & 1.18 & 1.06 & $1.31 *$ \\
\hline \multirow[t]{7}{*}{ Shin/ankle/foot } & Ankle sprains or joint injuries & 2.8 & 2.4 & 1.17 & 1.00 & $1.37 *$ \\
\hline & Calf strains & 1.8 & 1.7 & 1.06 & 0.88 & 1.28 \\
\hline & Achilles tendon injuries & 0.4 & 0.5 & 0.70 & 0.47 & 1.03 \\
\hline & Leg and foot fractures & 0.6 & 0.7 & 0.92 & 0.68 & 1.25 \\
\hline & Leg and foot stress fractures & 0.9 & 1.1 & 0.85 & 0.66 & 1.09 \\
\hline & Other leg/foot/ankle injuries & 1.5 & 1.6 & 0.96 & 0.79 & 1.18 \\
\hline & All leg/foot/ankle & 8.0 & 7.9 & 1.01 & 0.92 & 1.10 \\
\hline Medical illness & Medical illnesses & 2.2 & 1.9 & 1.15 & 0.97 & 1.37 \\
\hline All injuries & All injuries & 37.4 & 35.6 & 1.05 & 1.01 & $1.10 *$ \\
\hline
\end{tabular}

Notes: *Signifies $P<0.05$ difference. Cfa - Brisbane, Gold Coast, Sydney. Cfb - Melbourne, Geelong, Launceston. Csa - Adelaide, Perth.

Abbreviations: AC, acromioclavicular joint; ACL, anterior cruciate ligament; AFL, Australian Football League; Cfa, Humid Subtropical; Cfb, Maritime Temperate; $\mathrm{Cl}$, confidence interval; Csa, Mediterranean; MCL, medial collateral ligament; PCL, posterior cruciate ligament; RR, relative risk; N, north; S, south. 
were more common in teams based in the south, although this did not quite reach statistical significance $(P<0.07)$. There were nonsignificant trends towards more lumbar spine injuries and knee medial collateral ligament injuries in the AFL teams in warmer climates, whereas leg and foot stress fractures and knee posterior cruciate ligament injuries had higher rates in the AFL teams in cooler climates. Knee ACL injuries were $9 \%$ more likely in the warmer region teams but this increase was not statistically significant (-18\% to $46 \%$ ); however, knee injuries were significantly more likely in the warmer region teams.

Table 3 provides a comparison between southern (warmseason) UEFA teams and northern (cool-season) UEFA teams, recalculated from Waldén et al. ${ }^{15}$

\section{Discussion}

The current study reveals a very small but significant increase in injury incidence in the northern (warmer) part of Australia for the AFL. This is similar to an earlier study (Table 4) from the same cohort including data between seasons 1992 and 1998,13 making it more likely to be an accurate association. Many of the injuries that were statistically more likely in warmer region teams in the AFL in the 1990s were also more likely in the current study, such as quadriceps strains, knee injuries, and ankle sprains. However, the strength of the association generally appears to be lower than it once was. This may indicate that some of the possible ground-related risk factors - for example, exclusive use of warm-season grasses without oversowing of ryegrass - have been addressed by northern venues in recent years as a result of previously published information. , $^{6,20}$

The methodology of this study has a few limitations. Despite the broad application of the Köppen-Geiger climate system worldwide, ${ }^{19}$ there is still quite a lot of variation amongst the different climate zones in different parts of the world. Cfa zone was included in the 'warm' zone in the AFL study as winter temperatures in this zone in Australia

Table 3 Comparison between southern (warm-season) UEFA teams and northern (cool-season) UEFA teams, recalculated from Walden et al $^{15}$

\begin{tabular}{|c|c|c|c|c|c|c|}
\hline \multirow[t]{3}{*}{ Body area } & \multirow[t]{3}{*}{ Injury category } & \multicolumn{2}{|c|}{ Injury incidence } & \multirow{3}{*}{$\begin{array}{l}\text { RR } \\
\text { S:N } \\
\text { (warm:cool) }\end{array}$} & \multicolumn{2}{|c|}{$95 \% \mathrm{Cl}$} \\
\hline & & \multirow{2}{*}{$\begin{array}{l}\text { Southern } \\
\text { warmer } \\
\text { Csa, Csb }\end{array}$} & \multirow{2}{*}{$\begin{array}{l}\text { Northern } \\
\text { cooler } \\
\mathrm{Cfa}, \mathrm{Cfb} \\
\end{array}$} & & \multirow[t]{2}{*}{ Low } & \multirow[t]{2}{*}{ High } \\
\hline & & & & & & \\
\hline \multirow[t]{3}{*}{ Head/neck } & Concussion & 0.02 & 0.05 & 0.32 & 0.10 & 1.06 \\
\hline & Head fractures & 0.04 & 0.04 & 1.06 & 0.45 & 2.49 \\
\hline & All head/neck & 0.07 & 0.13 & 0.56 & 0.31 & 1.02 \\
\hline \multirow[t]{2}{*}{ Shoulder/arm/elbow } & Shoulder sprains and dislocations & 0.04 & 0.09 & 0.52 & 0.25 & 1.11 \\
\hline & All shoulder/arm/elbow & 0.07 & 0.15 & 0.48 & 0.27 & $0.85 *$ \\
\hline \multirow[t]{2}{*}{ Forearm/wrist/hand } & Forearm/wrist/hand fractures & 0.04 & 0.04 & 1.11 & 0.50 & 2.48 \\
\hline & All forearm/wrist/hand & 0.07 & 0.06 & 1.18 & 0.62 & 2.21 \\
\hline \multirow[t]{3}{*}{ Trunk/back } & Rib and chest wall injuries & 0.04 & 0.06 & 0.67 & 0.30 & $1.5 \mathrm{I}$ \\
\hline & Lumbar and thoracic spine injuries & 0.10 & 0.22 & 0.45 & 0.28 & 0.74 \\
\hline & All trunk/back & 0.19 & 0.40 & 0.48 & 0.33 & $0.68 *$ \\
\hline \multirow[t]{4}{*}{ Hip/groin/thigh } & Groin strains and osteitis pubis & 0.67 & 0.77 & 0.87 & 0.71 & 1.07 \\
\hline & Hamstring strain & 0.97 & 0.95 & 1.02 & 0.86 & 1.21 \\
\hline & Quadriceps strain & 0.38 & 0.43 & 0.87 & 0.66 & 1.14 \\
\hline & All hip/groin/thigh & 2.24 & 2.49 & 0.90 & 0.81 & 1.00 \\
\hline \multirow[t]{6}{*}{ Knee } & $\mathrm{ACL}$ & 0.11 & 0.05 & 2.31 & 1.30 & $4.08 *$ \\
\hline & $\mathrm{MCL}$ & 0.26 & 0.32 & 0.83 & 0.60 & 1.14 \\
\hline & $\mathrm{PCL}$ & 0.01 & 0.01 & 0.67 & 0.08 & 5.73 \\
\hline & Knee cartilage and meniscus injuries & 0.15 & 0.19 & 0.75 & 0.49 & 1.15 \\
\hline & Knee and patella tendon injuries & 0.14 & 0.12 & 1.21 & 0.77 & 1.91 \\
\hline & All knee & 1.13 & 1.42 & 0.80 & 0.68 & $0.93 *$ \\
\hline \multirow[t]{5}{*}{ Shin/ankle/foot } & Ankle sprains or joint injuries & 0.68 & 0.60 & 1.13 & 0.92 & 1.39 \\
\hline & Calf strains & 0.32 & 0.32 & 1.00 & 0.75 & 1.35 \\
\hline & Achilles tendon injuries & 0.41 & 0.44 & 0.93 & 0.72 & 1.20 \\
\hline & Leg and foot fractures/stress fractures & 0.11 & 0.14 & 0.77 & 0.47 & 1.26 \\
\hline & All shin/ankle/foot & 1.28 & 1.43 & 0.90 & 0.78 & 1.04 \\
\hline All & Match & 18.03 & 20.87 & 0.86 & 0.78 & $0.95 *$ \\
\hline
\end{tabular}

Note: *Signifies $P<0.05$ difference.

Abbreviations: ACL, anterior cruciate ligament; Cfa, Humid Subtropical; Cfb, Maritime Temperate; Cl, confidence interval; Csa, Mediterranean; Csb, Dry-summer Subtropical; MCL, medial collateral ligament; PCL, posterior cruciate ligament; RR, relative risk; UEFA, Union of European Football Associations; N, north; S, south. 
Table 4 Comparison of injury incidence in Victorian and non-Victorian teams (1992-1998) (injuries/team/season)

\begin{tabular}{|c|c|c|c|c|c|}
\hline \multirow[t]{2}{*}{ Injury category } & \multicolumn{2}{|l|}{ Incidence } & \multirow{2}{*}{$\frac{\mathbf{R R}}{\mathbf{N}: \mathbf{S} \text { (warm:cool) }}$} & \multicolumn{2}{|c|}{$95 \% \mathrm{Cl}$} \\
\hline & Northern & Southern & & Low & High \\
\hline Concussion & 0.9 & 0.9 & 1.00 & 0.65 & 1.53 \\
\hline Other head and neck injuries & I.I & 0.9 & 1.29 & 0.87 & 1.93 \\
\hline Shoulder joint injuries & 1.1 & 1.0 & 1.10 & 0.75 & 1.63 \\
\hline Acromioclavicular injuries & 1.1 & 0.9 & 1.21 & 0.81 & 1.81 \\
\hline Upper limb fractures & 1.6 & 1.8 & 0.88 & 0.64 & 1.20 \\
\hline Other upper limb injuries & 0.6 & 0.6 & 1.04 & 0.62 & 1.73 \\
\hline Trunk injuries & 1.2 & 1.2 & 0.97 & 0.68 & 1.39 \\
\hline Back and buttock injuries & 2.0 & 2.5 & 0.81 & 0.62 & 1.07 \\
\hline Groin and hip injuries & 5.2 & 3.5 & 1.48 & 1.23 & $1.79 *$ \\
\hline Hamstring strain injuries & 7.2 & 8.0 & 0.90 & 0.78 & 1.04 \\
\hline Quadriceps strain injuries & 2.7 & 2.0 & 1.32 & 1.03 & $1.7 I^{*}$ \\
\hline Knee ACL & 1.1 & 0.7 & I.7। & 1.13 & $2.58^{*}$ \\
\hline Knee MCL & 1.1 & 1.2 & 0.87 & 0.60 & 1.27 \\
\hline Knee PCL & 0.4 & 0.6 & 0.72 & 0.40 & 1.30 \\
\hline Knee cartilage/degenerative injuries & 1.9 & 1.3 & 1.45 & 1.06 & $1.98 *$ \\
\hline Other knee injuries & 2.0 & 1.2 & 1.66 & 1.21 & $2.26^{*}$ \\
\hline Leg fractures & 0.6 & 0.4 & 1.36 & 0.80 & 2.29 \\
\hline Leg stress fractures & 0.4 & 0.3 & 1.11 & 0.54 & 2.31 \\
\hline Calf muscle strain injuries & 2.4 & 1.8 & 1.35 & 1.02 & $1.77^{*}$ \\
\hline Lower limb hematomas ('corks') & 2.2 & 1.8 & 1.19 & 0.90 & 1.58 \\
\hline Foot fractures (including stress fractures) & 0.5 & 0.7 & 0.76 & 0.45 & 1.29 \\
\hline Ankle joint injuries & 3.8 & 2.2 & 1.71 & 1.36 & $2.15^{*}$ \\
\hline Other lower limb injuries & 1.5 & 1.8 & 0.85 & 0.62 & 1.17 \\
\hline Medical illnesses & 1.8 & 1.8 & 1.03 & 0.76 & 1.39 \\
\hline Total injuries & 44.4 & 39.1 & 1.14 & 1.07 & $1.21 *$ \\
\hline
\end{tabular}

Notes: *Indicates significantly higher risk of injury for northern teams $\left(P<0.05\right.$ or $95 \%$ confidence). Reprinted with permission from AGCSA. ${ }^{13}$

Abbreviations: $\mathrm{ACL}$, anterior cruciate ligament; $\mathrm{Cl}$, confidence interval; $\mathrm{MCL}$, medial collateral ligament; $\mathrm{PCL}$, posterior cruciate ligament; $\mathrm{RR}$, relative risk; $\mathrm{N}$, north; $\mathrm{S}$, south.

(Brisbane and Sydney) are very mild. In the UEFA study, the stadiums in zones that were classified as Cfa, eg, Milan and Northern Italy (Figure 12), were included in the cool climate group. The $\mathrm{Cfb}$ zone also has major variation between Europe and Australia. In Melbourne, Australia, winter minimums are never below freezing, so perennial ryegrass survives in winter without requiring underground heating. By contrast, $\mathrm{Cfb}$ zone in most of Europe is associated with overnight minimums of below freezing, so that underground heating or grass replacement is required to preserve grass cover in winter. Still, in all $\mathrm{Cfb}$ zones, warm-season grasses become dormant in winter and the predominant grass profile will be cool-season grasses only. Despite these limitations, the distinction in climate categorization between warm and cool probably needs to reflect whether the dominant natural grass species of the profile is likely to be warm-season (Figures 3 and 4) or cool-season (Figures 7-11).

Warm-season grasses tend to have greater thatch formation because of higher lateral growth (as can be seen in Figures 3-11). ${ }^{6} 14$ Although we expect that warm-season grasses will lead to higher shoe-surface traction measurements, ${ }^{4,6,14,21}$ the fact that no such measurements were made is a further limitation of this study. An analysis of data from multiple studies suggests that none of the easilymeasured risk factors (ambient temperature, wet/dry days) are clear injury risk factors. Shoe-surface traction, which is not easily measured, could be a risk factor for some injuries. This is a hypothesis consistent with much of the observed data, although it is generated from indirect observations (eg, grass types, climate zones). A recent study involving American football played on natural grass and artificial turf did show increased injury risk associated with higher rotational traction directly measured for each player at the start of the season. ${ }^{22}$ The next phase of studies in this area will ideally include some papers that individually measure shoe-surface traction for all particular players/shoes on all of the particular days under surveillance. This, of course, would be difficult to do in practice as measurements are time consuming and would not necessarily be accepted by players as part of their routine pre-game preparation.

There does seem to be some consistency in some of the reported trends between the published studies. Knee ACL injuries and ankle ligament sprains appear to be more common in both the warmer regions of Australia ${ }^{10}$ and the 
warmer regions of Europe. By contrast, Achilles tendon injuries appear to be more common in cooler climates in both Australia and Europe. It is therefore plausible to consider that perhaps a higher traction surface leads to greater risk of knee ACL injury and ankle ligament sprain, but that a lower traction (more slippery) surface leads to greater loads on the Achilles tendon.

It is worth noting that there were few differences between climate zones in either cohort with respect to upper body injuries. None of the differences in the AFL cohort reached statistical significance for upper limb, head, or neck injuries. There was a significant increase in shoulder/upper arm injuries in the cool climate-teams in the UEFA cohort, which is less likely to be related to surface conditions than differences seen in the lower limb injury profile.

With respect to muscle strains, none of the categories in the UEFA cohort reached statistical significance when comparing climate zones. In the AFL cohort, quadriceps strains were more common in warmer climate zones but none of the other muscle strains differed significantly between climate zones. No major conclusions can be drawn from the AFL quadriceps data in isolation, but it could be concluded that ambient temperature is unlikely to be a risk factor for muscle strain injury in general.

There are a few common trends in the warm- versus coolclimate-team injury profile across different football codes in different hemispheres. Importantly, there does not appear to be an overall trend that injuries from all categories are all more common in warmer or cooler climates. However, there are some specific injury categories that appear to be more likely in warmer environments, particularly ankle ligament sprains and ACL injuries, even though the increased point estimate of ACL injury incidence did not reach significance in this updated analysis. Conversely, Achilles tendon injuries may be more common in cooler climates. Further research is required in multiclimate injury surveillance systems to explore these early trends further. In particular, ACL injuries may be more likely in warmer climates due to surface factors, and, as these are serious and costly injuries, further exploration of this as a potential external risk factor is justified. If surface-related factors can be clearly connected with some lower limb injuries, then injury prevention measures related to these factors can be attempted.

\section{Disclosure}

JWO, JJO and HS directly or indirectly receive payments from the AFL primarily for injury surveillance consultancy. $\mathrm{MW}, \mathrm{MH}$ and JE directly or indirectly receive payments from UEFA primarily for injury surveillance consultancy.

\section{References}

1. Powell JW, Schootman M. A multivariate risk analysis of selected playing surfaces in the National Football League: 1980 to 1989. An epidemiologic study of knee injuries. Am J Sports Med. 1992;20(6): 686-694.

2. Ekstrand J, Timpka T, Hägglund M. Risk of injury in elite football played on artificial turf versus natural grass: a prospective two-cohort study. Br J Sports Med. 2006;40:975-980.

3. Hershman EB, Anderson R, Bergfeld JA, et al. An analysis of specific lower extremity injury rates on grass and FieldTurf playing surfaces in National Football League Games: 2000-2009 seasons. Am J Sports Med. 2012;40(10):2200-2205.

4. Orchard J. Is there a relationship between ground and climatic conditions and injuries in football? Sports Med. 2002;32(7):419-432.

5. Williams S, Hume PA, Kara S. A review of football injuries on third and fourth generation artificial turfs compared with natural turf. Sports Med. 2011;41(11):903-923.

6. Orchard JW, Chivers I, Aldous D, Bennell K, Seward H. Ryegrass is associated with fewer non-contact anterior cruciate ligament injuries than bermudagrass. Br J Sports Med. 2005;39:704-709.

7. Orchard J, Seward H, McGivern J, Hood S. Rainfall, evaporation and the risk of non-contact anterior cruciate ligament knee injuries in the Australian Football League. Med J Aust. 1999;170:304-306.

8. Orchard J, Rodas G, Til L, Ardevòl J, Chivers I. A hypothesis: could portable natural grass be a risk factor for knee injuries? J Sports $S c i$ Med. 2008;7(1):184-190.

9. Moses B, Orchard J, Orchard J. Systematic review: Annual incidence of ACL injury and surgery in various populations. Res Sports Med. 2012;20:157-179.

10. Janssen KW, Orchard JW, Driscoll TR, van Mechelen W. High incidence and costs for anterior cruciate ligament reconstructions performed in Australia 2003-2004 to 2007-2008: time for an anterior cruciate ligament register by Scandinavian model? Scand J Med Sci Sports. 2012;22:495-501.

11. Gianotti SM, Marshall SW, Hume PA, Bunt L. Incidence of anterior cruciate ligament injury and other knee ligament injuries: A national population-based study. J Sci Med Sport. 2009;12(6):622-627.

12. Jameson SS, Dowen D, James P, Serrano-Pedraza I, Reed MR, Deehan D. Complications following anterior cruciate ligament reconstruction in the English NHS. Knee. 2012;19:14-19.

13. Orchard J. The 'northern bias' for injuries in the Australian Football League. Australian Turfgrass Management. 2000;2(3):36-42.

14. Chivers I, Aldous D, Orchard J. The relationship of Australian football grass surfaces to anterior cruciate ligament injury. International Turfgrass Society Research Journal. 2005;10:327-332.

15. Waldén M, Hägglund M, Orchard J, Kristenson K, Ekstrand J. Regional differences in injury incidence in European professional football. Scand J Med Sci Sports. 2013;23:424-430.

16. Waldén M, Hägglund M, Ekstrand J. UEFA Champions League study: a prospective study of injuries in professional football during the 2001-2002 season. Br J Sports Med. 2005;39:542-546.

17. Orchard J, Seward H. Epidemiology of injuries in the Australian Football League, seasons 1997-2000. Br J Sports Med. 2002;36: $39-44$.

18. Orchard JW, Seward H, Orchard JJ. Results of 2 decades of injury surveillance and public release of data in the Australian football league. Am J Sports Med. 2013;41(4):734-741.

19. Kottek M, Grieser J, Beck C, Rudolf B, Rubel F. World map of the Koppen-Geiger climate classification updated. Meteorologische Zeitschrift. 2006;15:259-263.

20. Orchard J, Chivers I, Aldous D. Seasonal and Geographical Analysis of ACL Injury Risk in Australia. Sport Health. 2005;23(4):20-27.

21. Orchard J. ACL prevention in Norway and Australia. Sport Health. 2008;26(2):17-22

22. Wannop JW, Luo G, Stefanyshyn DJ. Footwear traction and lower extremity noncontact injury. Med Sci Sports Exerc. 2013;45(11):21372143. 


\section{Publish your work in this journal}

Open Access Journal of Sports Medicine is an international, Visit http://www.dovepress.com/testimonials.php to read real quotes peer-reviewed, open access journal publishing original research, from published authors.

reports, reviews and commentaries on all areas of sports

medicine. The manuscript management system is completely

online and includes a very quick and fair peer-review system.

Submit your manuscript here: http://www.dovepress.com/open-access-journal-of-sports-medicine-journal 